\title{
Analysis of Seepage Under Hydraulic Structures Using Slide Program
}

\author{
Hala Kathem Taeh Alnealy, Najm Obaid Salim Alghazali
}

Civil Engineering Department, Babylon University, Babylon, Iraq

Email address:

drnajm59@gmail.com (N. O. S. Alghazali), Halhhalh300@yahoo.com (H. K. T. Alnealy)

\section{To cite this article:}

Najm Obaid Salim Alghazali, Hala Kathem Taeh Alnealy. Analysis of Seepage Under Hydraulic Structures Using Slide Program. American Journal of Civil Engineering. Vol. 3, No. 4, 2015, pp. 116-124. doi: 10.11648/j.ajce.20150304.14

\begin{abstract}
In this study, "SLIDE" program was used to analyze seepage flow under the hydraulic structure through single and multi- layers soils and its effect on structures with inclined cut-off at downstream, at upstream, and at both of them. The distribution curves of uplift pressure along the floor had been reached as well as the distribution of exit gradient at downstream. In the first experiment which included hydraulic structure based at single layers, results are compared with the general case (no cut-off) obtained when using single cutoff, minimum value of the uplift pressure and seepage quantity occurred when using cutoff at upstream side with $\Theta=45^{\circ}$ which given decreasing $40.3 \%, 28.5 \%$ respectively and minimum value of exist gradient occur when using cutoff at downstream side with $\Theta 120^{\circ}$ which given decreasing $8.03 \%$. while using double cutoff minimum value of uplift pressure ,exist gradient ,seepage occur when using double inclined cutoff at upstream with $\Theta=45^{\circ}$ and downstream side with $\Theta 120^{\circ}$ which given decreasing $(42.1 \%, 8.03 \%, 30 \%)$ its contacted that using double cutoff given decreasing in each uplift pressure, exist gradient, seepage at the same time.
\end{abstract}

Keywords: Inclined Cutoff, Single Layer Soil, Multi Layers Soil, Finite Element Method

\section{Introduction}

The foundation soil of any structure should be given the greatest importance in analysis and design as compared with other parts of the structure, because failure in the foundation would destroy the whole structure. The differential head in water levels between the upstream and downstream affects the foundation and causes seepage flow (Selim 1947). The groundwater flow depends on the type of flow, the soil media and the boundary conditions. Seepage of water is one of the major problems which effects on hydraulic structures (Alsenousi and Mohamed 2008). The seepage problem can be analyzed and solved by using many methods solution such as the electrical analog models, empirical formulas, experimental works as well as numerical models (EL-Fitiany et al 2003). In this study a numerical model to determine flow net is adopted.

\section{Aim of the Study}

The main objectives of this work can be summarized bythe following points:

1. To steady the effect of position and inclination angle of cutoff wall on uplift pressure, exist gradient and seepage quantity in the foundation the hydraulic structure resting on single layer soil.

2. To steady the effect of position and inclination angle of cutoff wall on uplift pressure, exist gradient and seepage quantity in the foundation the hydraulic structure resting on multi layers soil.

\section{General Case Study}

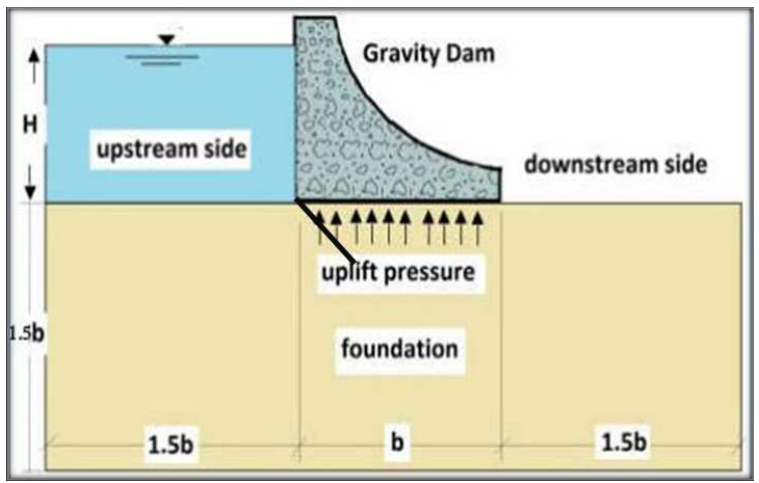

Fig. (1). General case study and boundary conditions. 
Finite element method was used to analyze the general case study shown in Fig.(1) using (SLIDE.5.0) program.

\section{Boundary Conditions}

The boundary conditions should be specified beforestarting the solution. For the steady state of a confinedflow, the boundary conditions are defined as follows:

- Reservoir Boundaries

The height of the water above these boundaries has always a known value, so that the pressure on any point of these boundaries is also known; so, the piezometric head distribution along the reservoir boundaries is constant; that is:

$$
H=H_{o}=\frac{p}{\gamma_{w}}+z
$$

- Impervious Boundary

Impervious boundary has the perpendicular velocityfunction on the surface equal to zero $\left(\frac{\partial H}{\partial n}=0\right)$.

\section{Finite Element Formulation of Seepage in Porous Medium}

The finite element method is a very powerful numerical method. It requires the use of digital computer because of the large number of computations involved. In ground water flow problems, one could imagine that a region is subdivided into small elements, these elements may be two, or threedimensional and joined to each other by nodes existing on the element boundaries. Such that for each element the flow is described in terms of the head in the nodal points, and that then a system of equations is obtained from the conditions that the flow must be continuous at each node (El-Katib, 2009The field variable model describing an approximate variation of piezometric head $(\mathrm{He})$ within the element is:

$$
H^{e}=\sum_{i=1}^{n} N_{i} H_{i}
$$

Where:

Hi: Nodal value of head; $H$, of the element;

$\mathrm{n}$ : Number of nodes per element;

$\mathrm{Ni}$ : Shape function of the element

It is possible to write Equation (3-1) in matrix form as follows [Zienkiewicz,1966]

$\mathrm{He}=[\mathrm{Ni}]\{\mathrm{Hi}\}$ Where:

]Ni]: shape function matrix;

\}Hi\}: vector matrix of nodal values.

The approximate solution for head variation, $\mathrm{H}$, over the whole domain is given as follows:

$$
H=\sum_{e=1}^{n_{e}}\left[N_{i}\right]\left\{H_{i}\right\}
$$

Where:

ne: is the total number of elements in the problem domain.

\section{Computer Program}

SLIDE v.5.0 it is analysis software built-in steady state groundwater analysis using finite element method slide 5 is a steady state flow model and will compute the piezometric head value at each node of the finite element mesh. From these values, flow lines and equipotential lines are plotted showing the resulting seepage net.

\section{Results and Discussion}

The Hydraulic Structure Resting on Single Layer Soil The problem of the effect of inclined cutoff and its location along the floor of hydraulic structure has been investigated on each of

\subsection{Effect of Inclined Cutoff and Its Position on the Uplift Pressure}

Figures (2) and (3) illustrates the relationship between the horizontal distance from the base of floor of hydraulic structure and pressure head, also this figures demonstrates of the influence of cutoff inclination and position on the uplift pressure generated along the base of hydraulic structure. When a cutoff subsist within upstream side with different angles inclination $\Theta\left(45^{\circ}, 90^{\circ}, 120^{\circ}\right)$ as shown in figure (432 ), the behavior of cutoff was noticed that the uplift pressure decreased as $(\Theta)$ decreased toward $\mathrm{U} / \mathrm{S}$ side for $\Theta\left(45^{\circ}, 90^{\circ}\right.$, $120^{\circ}$ ) where the maximum redaction in uplift pressure as compared with the general case (no cutoff) was $(40.3 \%$, $31.2 \%, 24.6 \%$ ) respectively.

So it is concluded that using upstream cutoff inclined towards the upstream side with $\Theta$ less than $90^{\circ}$ is beneficial in decreasing the uplift head because of increasing the length of creep which in turn increase the head loss.

The effect of downstream cutoff inclination angle on uplift pressure head that demonstrates in figure (3) for $\Theta\left(90^{\circ}\right.$, $120^{\circ}$ ) the maximum decreasing in uplift pressure as compared with the general case (no cutoff) was $(3.75 \%, 10 \%)$ respectively. It was noticed that the reduce in the uplift pressure was small to their placing of the cutoff inclination, therefore it can be neglected.

When using double cutoff posited at heel with $\Theta=90^{\circ}$ and toe with $\Theta=90^{\circ}$ as shown in figure(4), the uplift pressure reduced and the maximum decreasing in value of uplift pressure as compared with the general case (no cutoff) was $40.93 \%$. 


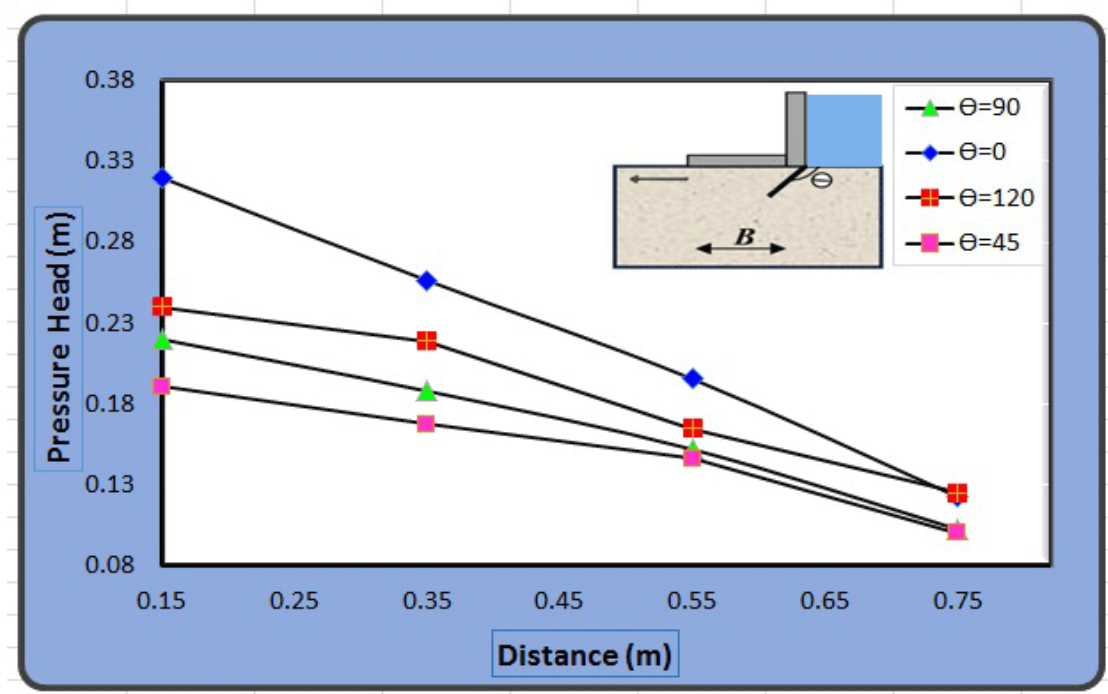

Fig. (2). Variation of uplift head under hydraulic structureresting on single layer with (U/S) cut-off for different values of $\Theta$.

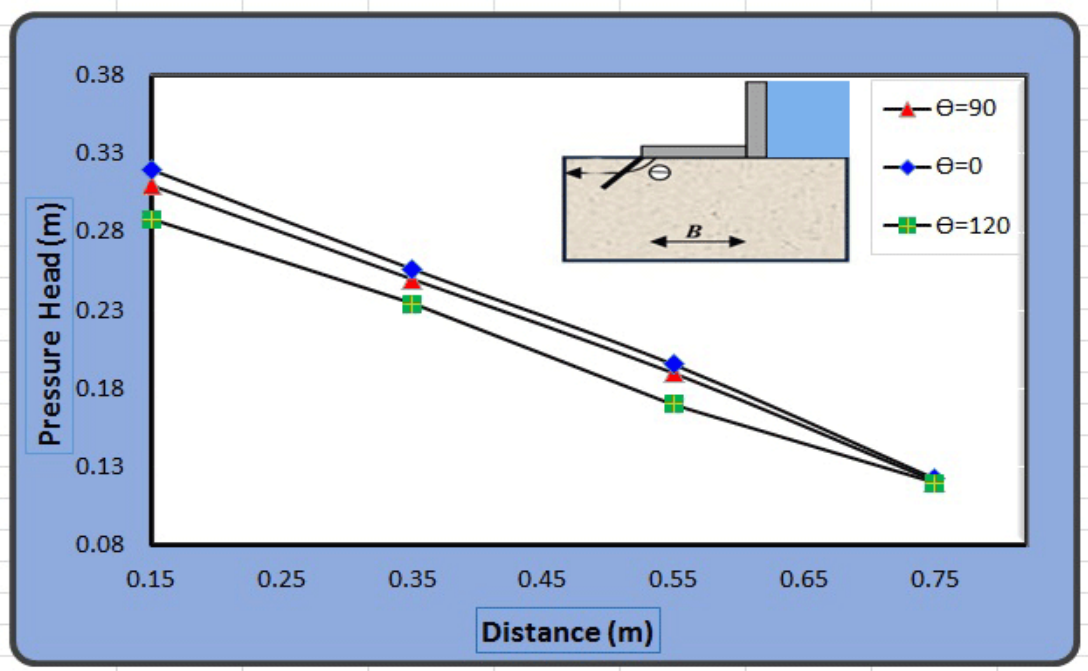

Fig. (3). Variation of uplift head under hydraulic structure resting on single layer-with (D/S) cut-off for different values of $\Theta$.

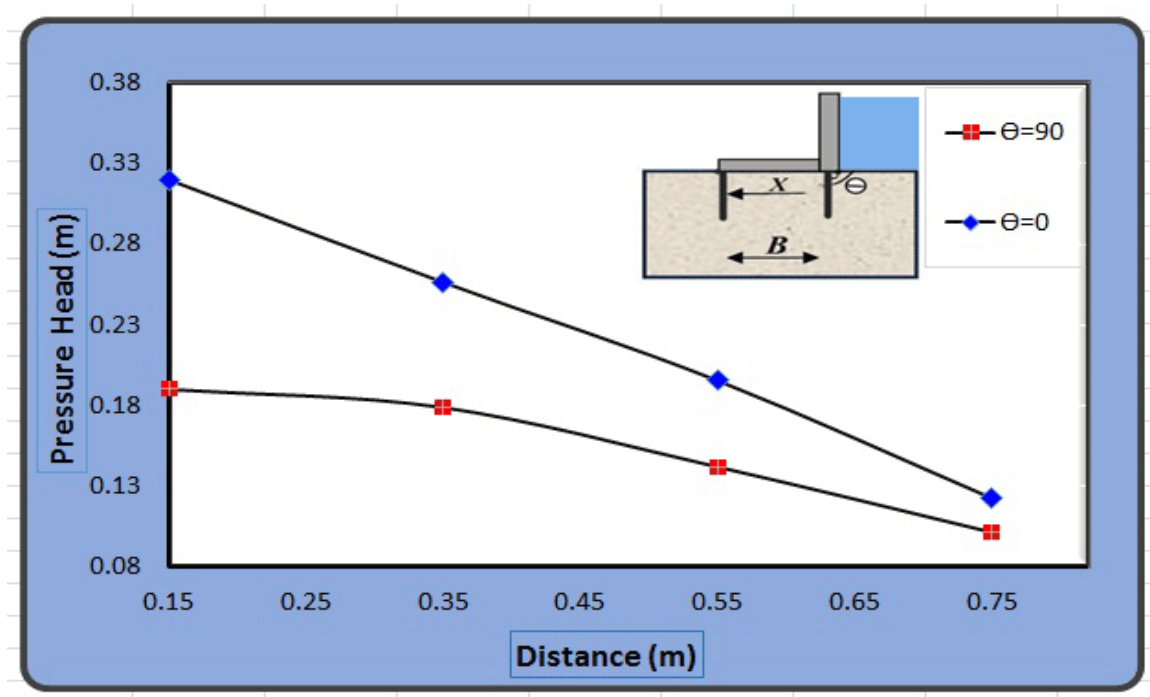

Fig. (4). Variation of uplift head under hydraulic structure resting on single layer - with double cutoff $U / S \theta=90$ and $D / S \theta=90$. 


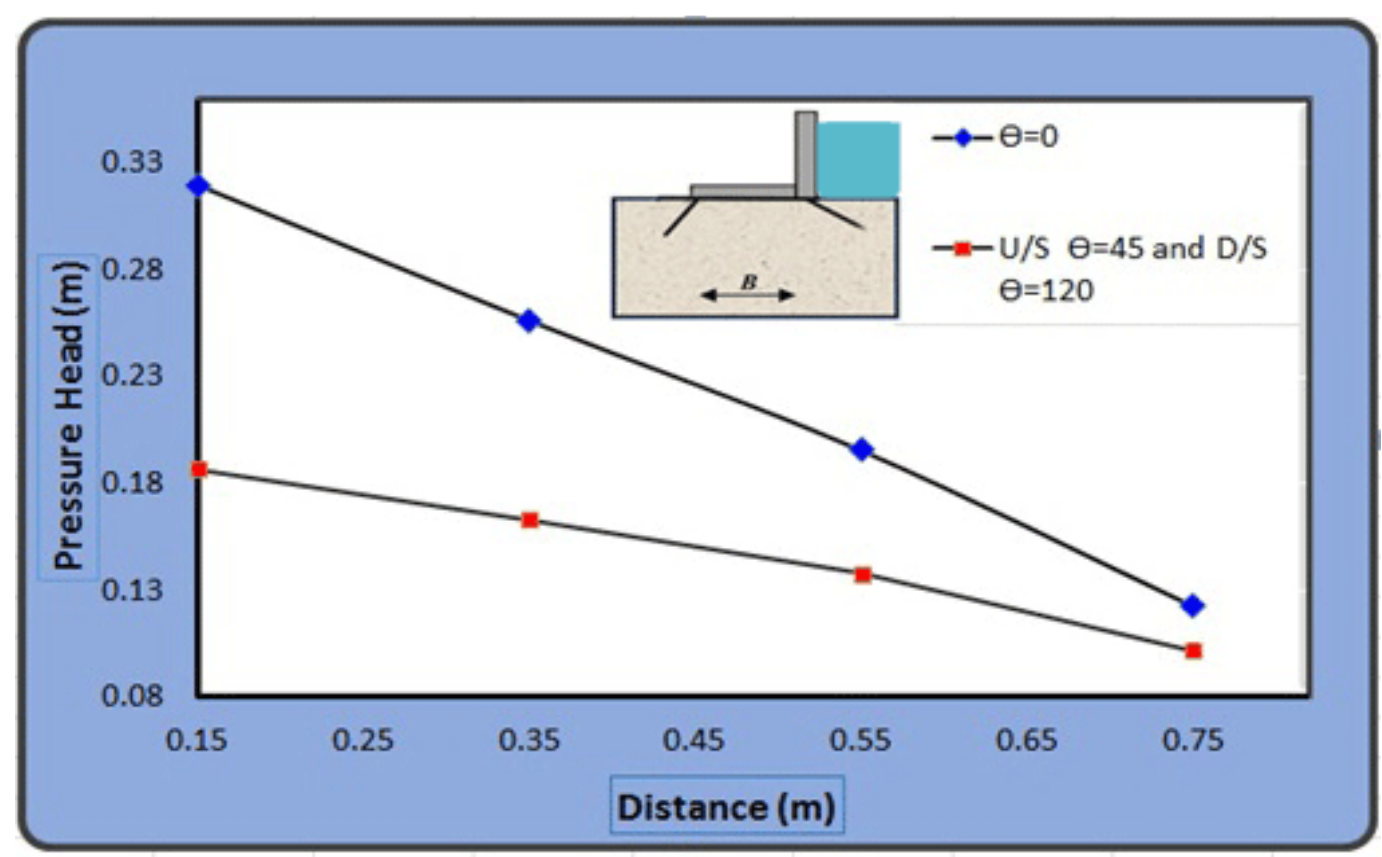

Fig. (5). Variation of uplift head under hydraulic structureresting on single layer - with $U / S \theta=45$ and $D / S \theta=120$.

The effect of using double inclined cutoff positioned at upstream side with $\Theta=45^{\circ}$ and downstream side with $\Theta=120^{\circ}$ is shown in figure (5). Which indicate that the value of uplift pressure decreases significantly to $42.01 \%$ as compared with the general case (no cutoff).

\subsection{Effect of Inclined Cutoff and Its Position on the Exit Gradient}

Figures (6) and (7) demonstrates the relationship between the horizontal distance from downstream side and exist gradient, also this figures show the influence of cutoff inclination and position on the exist gradient generated in the downstream side of hydraulic structure resting on sandy silty clay. In figure (6) illustrate the effect of cutoff inclination angle on exit gradient distribution along downstream side hydraulic structure with upstream inclined cutoff. It can be seen that values for exit gradient low decreased if the cut-off is inclined towards downstream side ( $\Theta$ is more than $90^{\circ}$ ), were the redaction in values of exit gradient for $\Theta$ $\left(45^{\circ}, 90^{\circ}, 120^{\circ}\right)$, the maximum redaction in exist gradient compared with the general case (no cutoff), were $(1.25 \%$, $1.78 \%, 3.21 \%$ ) respectively. It's shown that a slight decrease in the magnitude of the exist gradient when the cutoff posited in upstream side of the hydraulic structure. The factor of safety against piping calculated for this case in Table (1).

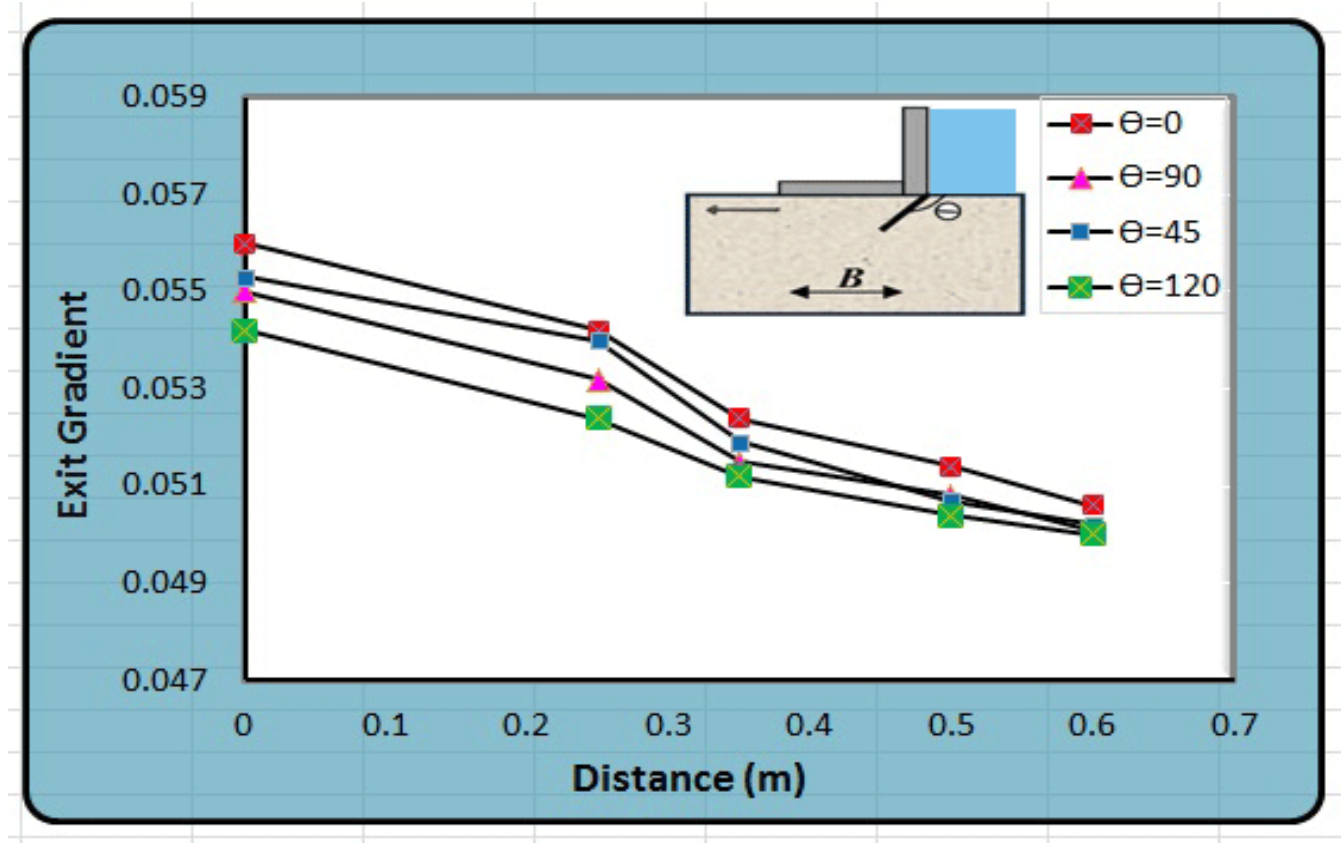

Fig. (6). Variation of exit gradient for a hydraulic structure resting on single layer-with (U/S) cut-off for different values of $\Theta$. 
Table (1). The factor of safety against piping for a hydraulic structure resting on single layer - when cutoff at $U / S$ with different values of $\theta$.

\begin{tabular}{lll}
\hline U/S Cut-off Inclination & $\max$ (exist gradient) & Fs \\
\hline $0^{\circ}$ & 0.4 & 2.47 \\
$45^{\circ}$ & 0.382 & 2.586 \\
$90^{\circ}$ & 0.375 & 2.63 \\
$120^{\circ}$ & 0.362 & 2.729 \\
\hline
\end{tabular}

As the cutoff posited in downstream side of hydraulic structure, the exit gradient decreased as $(\Theta)$ increases toward the $\mathrm{D} / \mathrm{S}$ side for $\Theta\left(90^{\circ}\right.$ and $\left.120^{\circ}\right)$, where the maximum decreasing in exist gradient as illustrates in figure (7), was (3.57\% 5.36\%)respectively,as compared with the general case (no cutoff), So it is concluded that using downstream cutoff inclined towards toe with $\Theta=120^{\circ}$ is beneficial in decreasing the value of exit gradient along downstream of the hydraulic structure, the factor of safety against piping phenomenon of this case can be calculated as shown in Table (2).

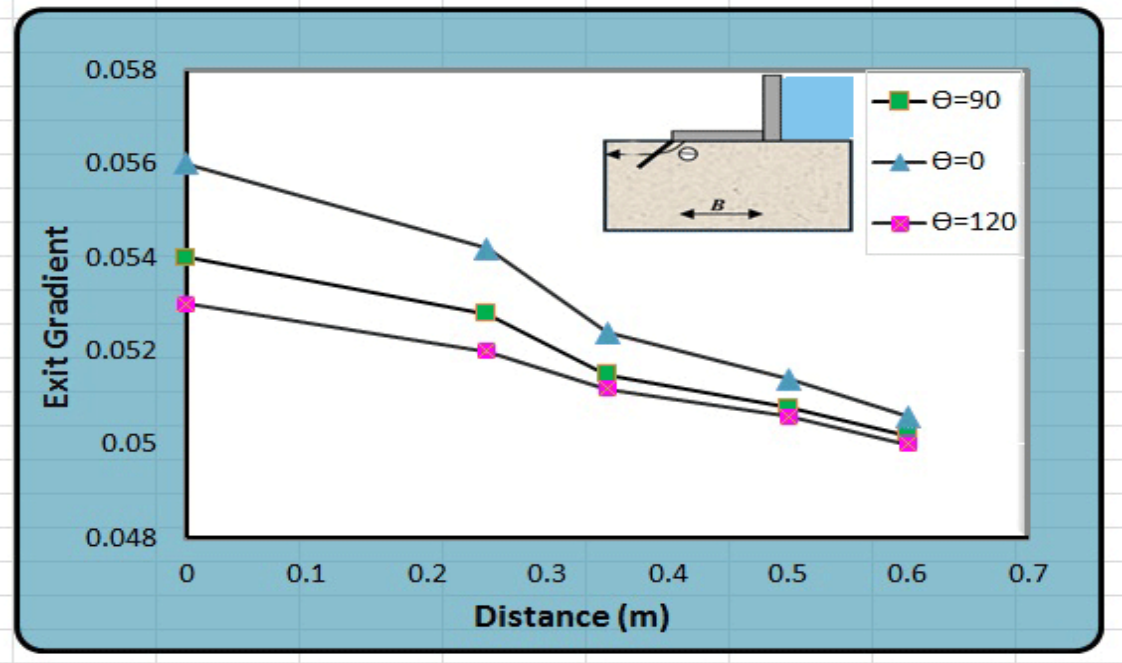

Fig. (7). Variation of exit gradient for a hydraulic structureresting on single layer - with (D/S) cut-off for different values of $\theta$.

Table (2). The factor of safety against piping for a hydraulic structure resting on single layer - when cutoff at $D / S$ with different values of $\Theta$.

\begin{tabular}{lll}
\hline U/S Cut-off Inclination & max (exist gradient) & Fs \\
\hline $0^{\circ}$ & 0.4 & 2.47 \\
$90^{\circ}$ & 0.35 & 2.82 \\
$120^{\circ}$ & 0.31 & 3.18 \\
\hline
\end{tabular}

The percentage decline in the value of exist gradient when using double cutoff at heel with $\Theta=90$ and toe of hydraulic structure with $\Theta=90$ was $6.11 \%$, as shown in figure (8) compared with the general case (no cutoff).

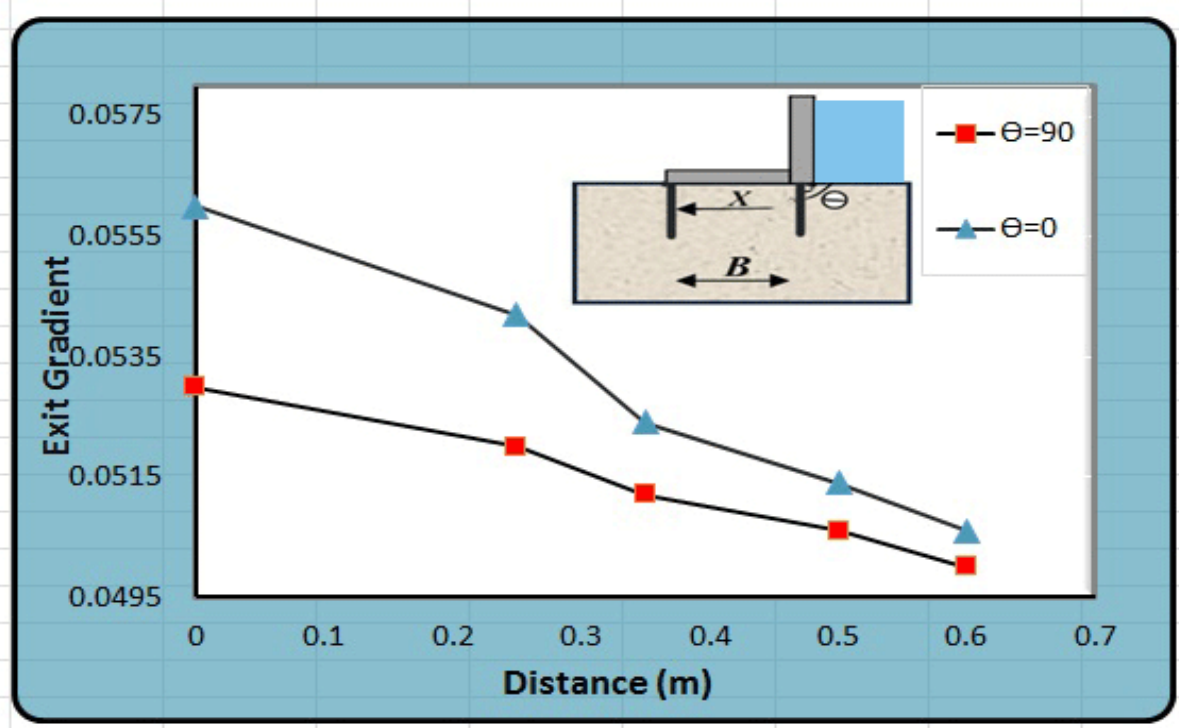

Fig. (8). Variation of exit gradient along downstream hydraulic structureresting on single layer with inclined U/S $\theta=90$ and $D / S \theta=90$.

High value in value factor of safety against piping occur when using double cutoff in the U/S with $\Theta=45^{\circ}$ and $D / S$ 
with inclined $\Theta=120^{\circ}$ as shown in figure (9) were the decreasing in exist gradient was $8.03 \%$ as compare with general case(no cutoff). So it is concluded that using double inclined cutoff with $\Theta=45^{\circ}$ at heel and $120^{\circ}$ is beneficial to give perfect decreasing in exist gradient .

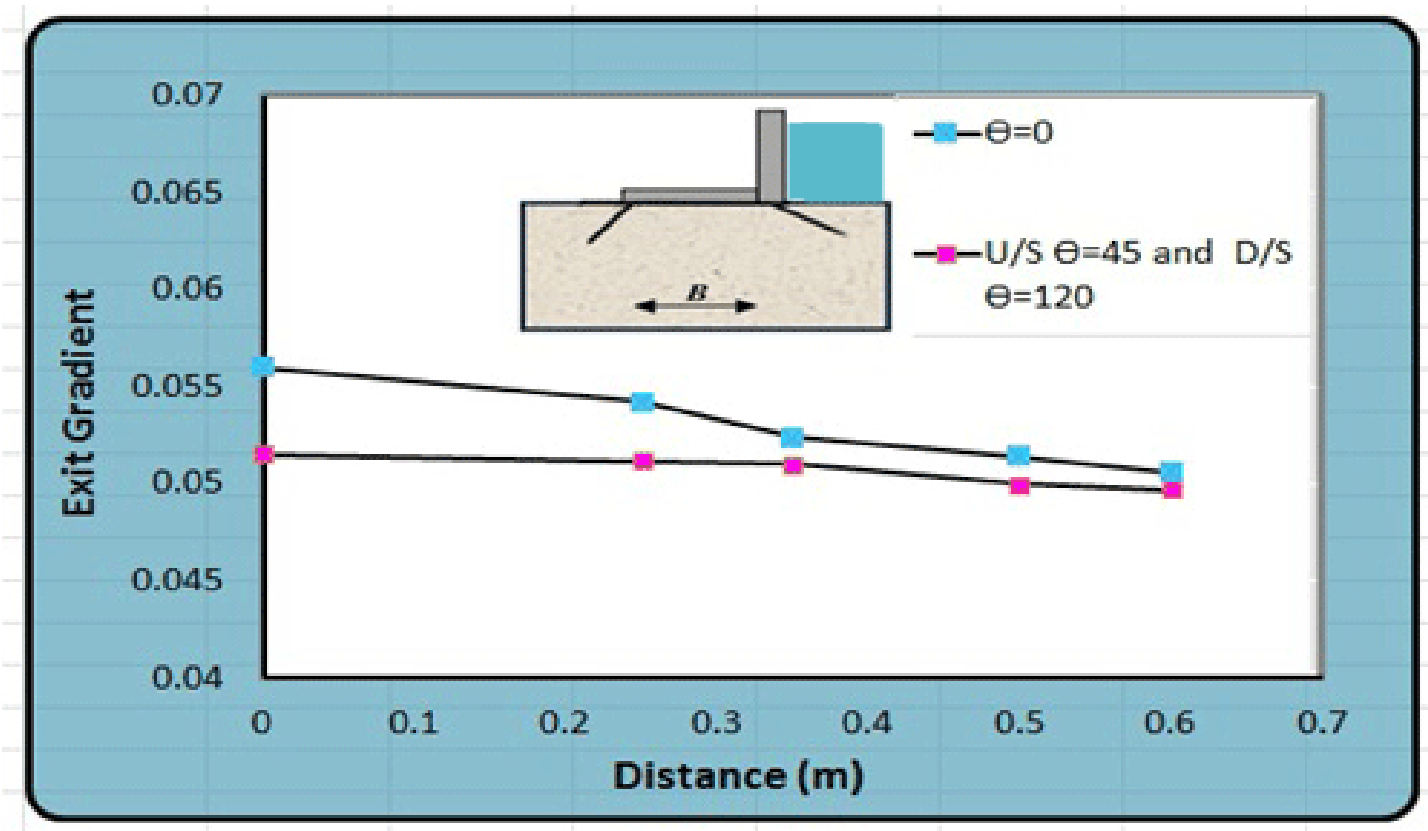

Fig. (9). Variation of exit gradient along downstream hydraulic structure resting on single layer - sandy silty clay with inclined $U / S \quad \theta=45$ and $D / S$ $\theta=120$.

\subsection{Effect of Cutoff Position and Inclination on the Seepage Quantity}

Figure (10) and (11) illustrate the influence of cutoff inclination on the seepage quantity, for the cutoff inclined in upstream side of hydraulic structure as shown in figure (10), noticed that the seepage under the hydraulic structure decreased as $(\Theta)$ decreased toward $\mathrm{U} / \mathrm{S}$ side for $\Theta\left(45^{\circ}\right.$, $90^{\circ}, 120^{\circ}$ ) where the maximum decreasing in seepage compared with the general case (no cutoff) was $(28.5 \%$, $23 \%, 6.34 \%$ ) respectively, so it is concluded that using upstream cutoff inclined towards the upstream side with $\Theta$ less than $90^{\circ}(\Theta=45)$ beneficial in decreasing the seepage quantity because of increasing the length of creep which in turn increase the head loss due to decrease the seepage quantity at the outlet .

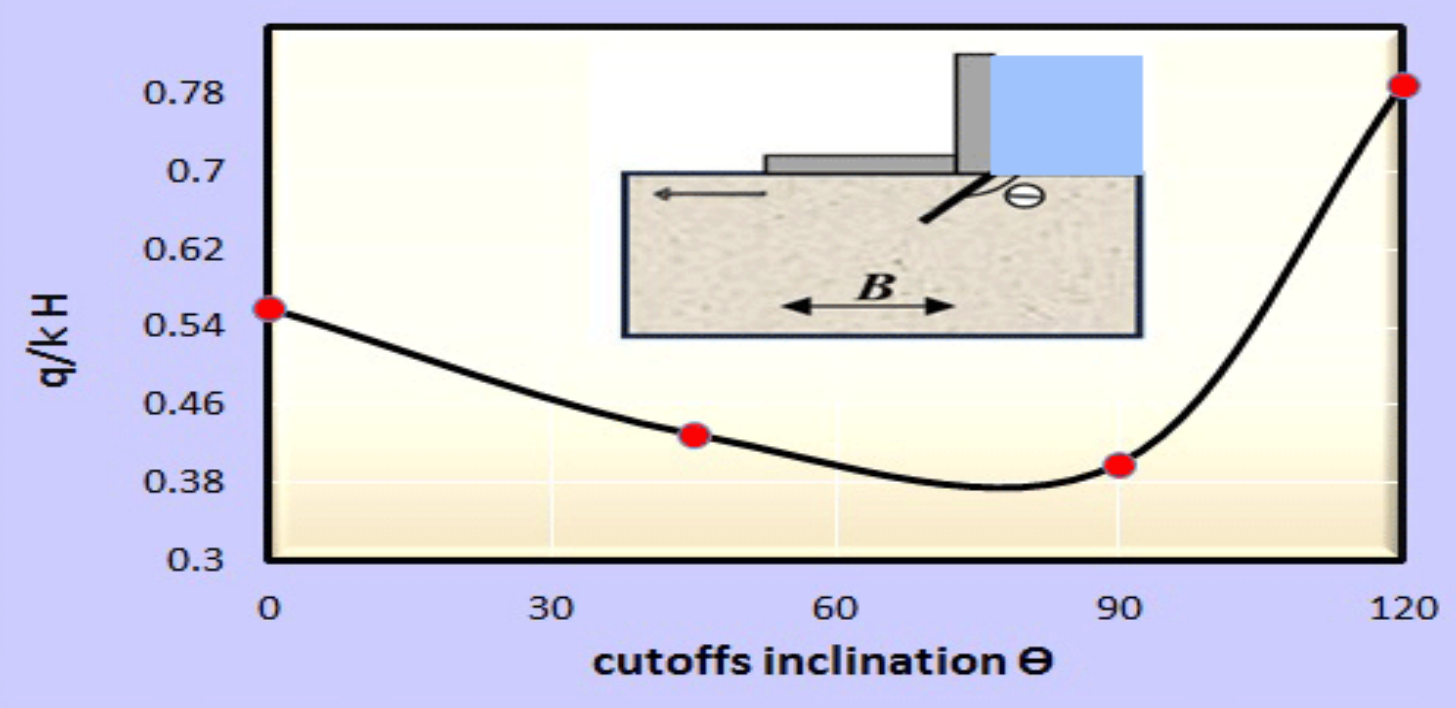

Fig. (10). Variation of Seepage quantity under hydraulic structure resting on single layer with (U/S) cut-off for different values of $\Theta$.

In figure(11) when the cutoff posited at the toe, the value of seepage decreased as $(\Theta)$ increased toward $\mathrm{D} / \mathrm{S}$ side for $\Theta$ 
$\left(90^{\circ}, 120^{\circ}\right)$ and the maximum decreasing in seepage compared with the general case (no cutoff) was $(12.6 \%$,

$28.57 \%$ ) respectively.

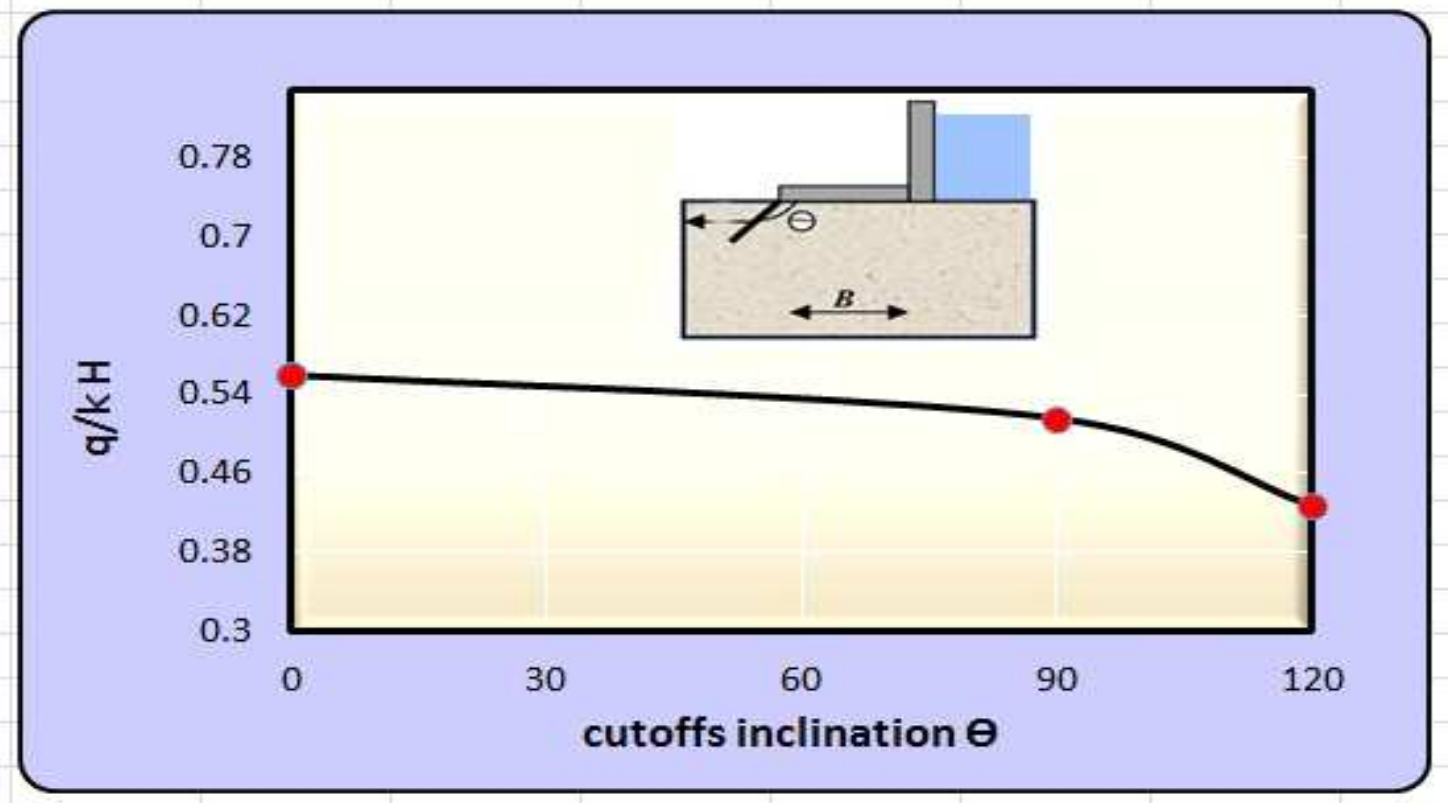

Fig.(11). Variation of Seepage quantity under hydraulic structure resting on single layer with (D/S) cut-off for different values of $\Theta$.

When cutoff positioned in $\mathrm{U} / \mathrm{S}$ with $\Theta=90$ and $\mathrm{D} / \mathrm{S}$ with $\Theta=90$ the seepage quantity reduced to $30.156 \%$, and when cutoff at $\mathrm{U} / \mathrm{S}$ with $\Theta=45^{\circ}$ and $\mathrm{D} / \mathrm{S}$ with $\Theta=120^{\circ}$ andseepage quantity reduced to $30.3 \%$ the compared with the general case (without cutoff).All results of above discussed cases were summarized in table (3).

Table (3). Effect of cut-off inclination on seepage controlfor hydraulic structure resting on single layer.

\begin{tabular}{|c|c|c|c|c|c|c|c|}
\hline \multicolumn{8}{|c|}{ Maximum redaction according to the general case $\theta=0$ (no cutoff) } \\
\hline & \multicolumn{3}{|c|}{ Cutoff at $\mathrm{U} / \mathrm{S}$} & \multicolumn{2}{|c|}{ Cutoff at $D / S$} & \multicolumn{2}{|c|}{ Double cutoff at $U / S$ and $D / S$} \\
\hline & $\theta=45^{0}$ & $\theta=90^{0}$ & $\theta=120^{0}$ & $\theta=90^{0}$ & $\theta=120^{0}$ & $\mathrm{U} / \mathrm{S}, \mathrm{D} / \mathrm{s} \mathbf{\theta}=90^{0}$ & 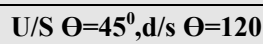 \\
\hline Uplift pressure & $40.31 \%$ & $31.25 \%$ & $24.68 \%$ & $3.75 \%$ & $10 \%$ & $40.99 \%$ & $42.01 \%$ \\
\hline Exit gradient & $1.25 \%$ & $1.78 \%$ & $3.21 \%$ & $3.57 \%$ & $5.35 \%$ & $5.35 \%$ & $8.03 \%$ \\
\hline Seepage & $28.5 \%$ & $23 \%$ & $6.34 \%$ & $12.6 \%$ & $28.75 \%$ & $30.15 \%$ & $30.3 \%$ \\
\hline
\end{tabular}

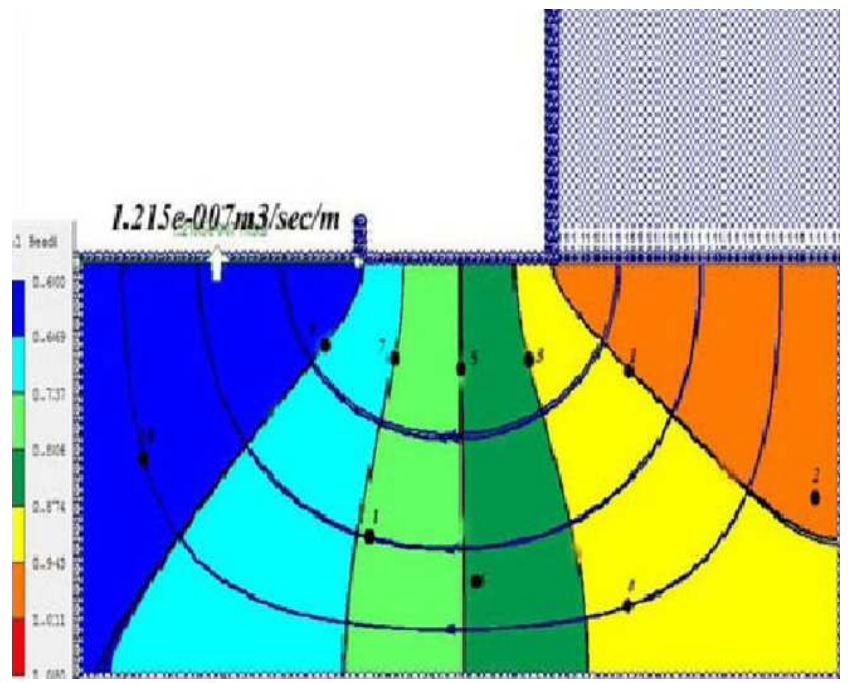

general case (no cutoff)

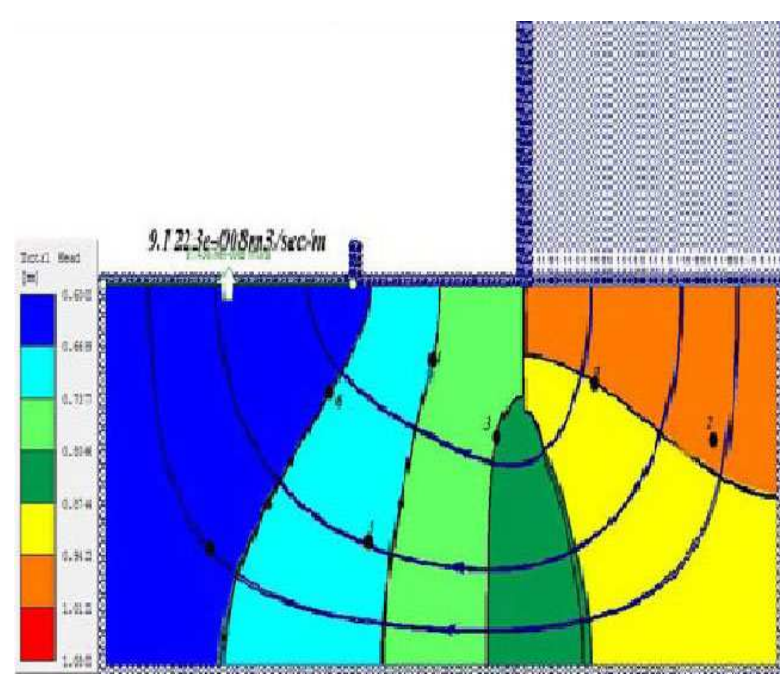

cutoff at the upstream side $\Theta=90$ 


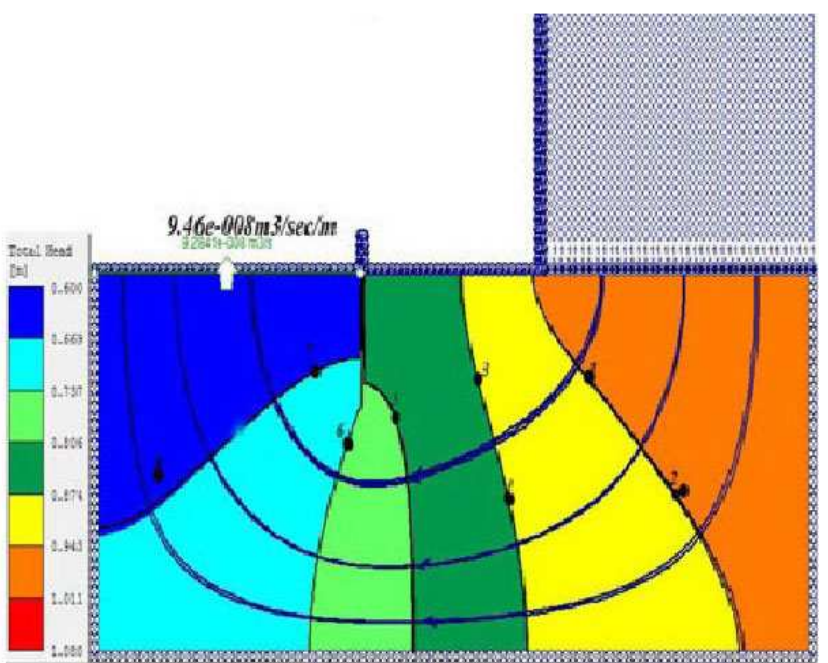

(cutoff at the downstream side $\Theta=90$ )

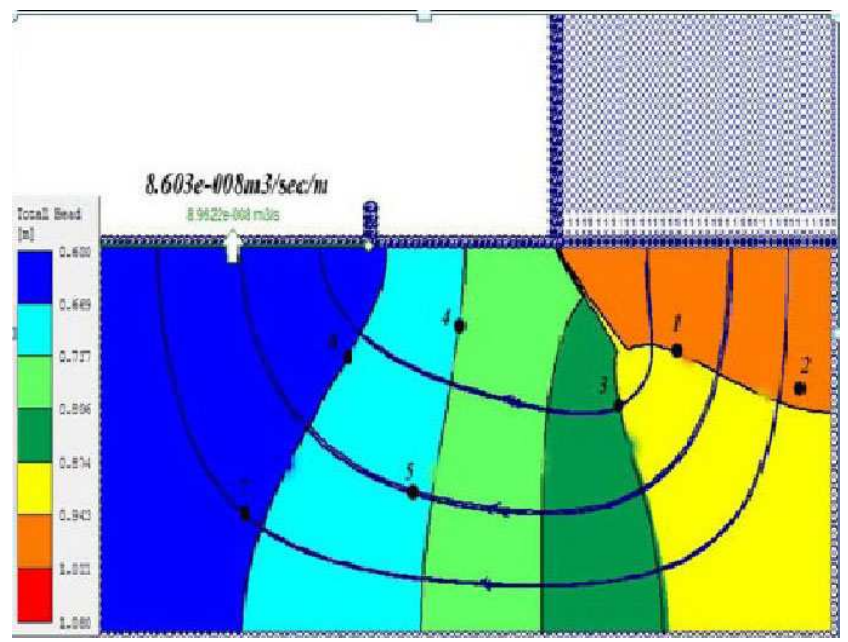

(cutoff at the upstream side $\Theta=45$ )

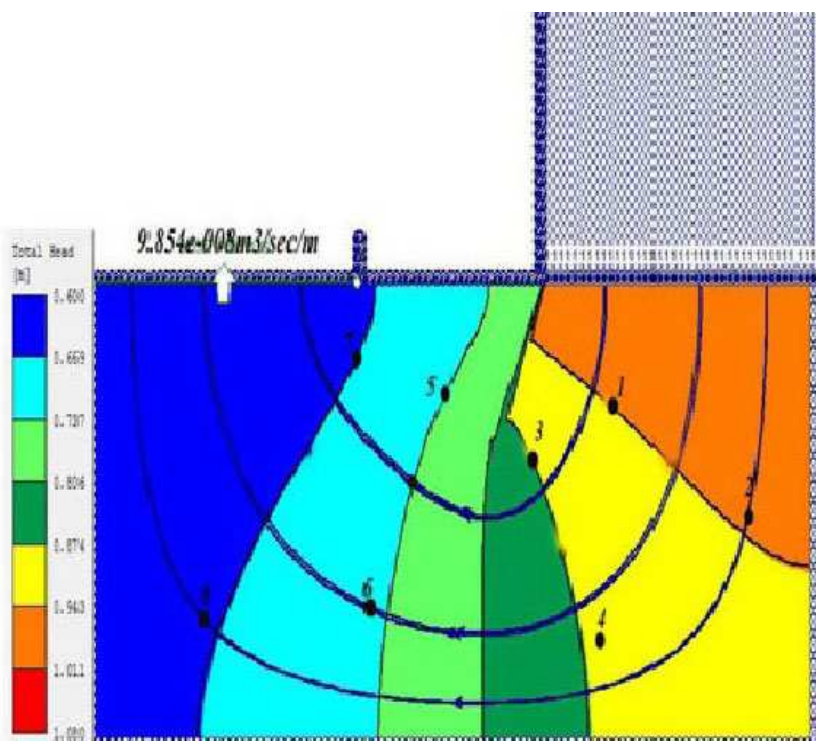

(cutoff at the upstream side $\Theta=120$ )

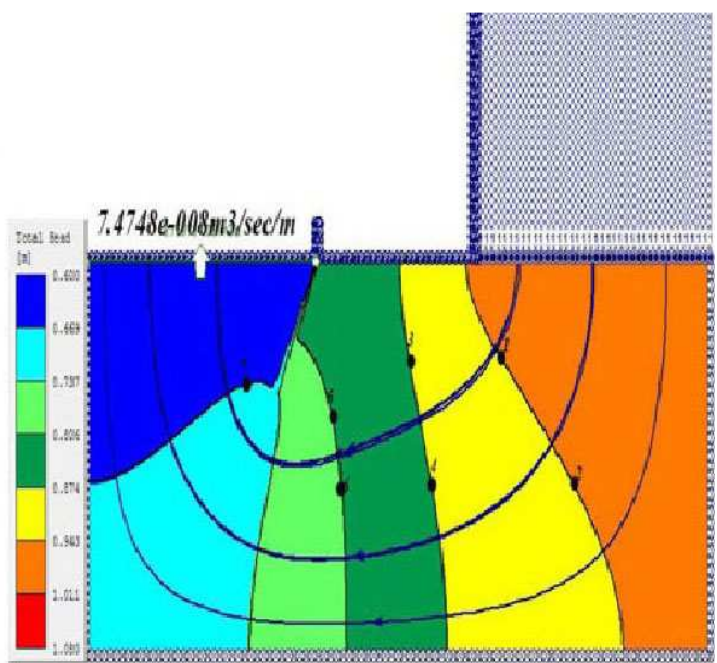

(cutoff at the downstream side $\Theta=120$

Fig. (12). The model images for second experiment included hydraulic structure resting on single layer.

\section{Conclusions and Recommendations}

In the conducted research, finite element method used to analyze the seepage flow through soil foundation under hydraulic structures and control of seepage flow. Based on the theoretical application models, the following main conclusions can be explained

- Using an inclined cut-off towards the upstream side with $\Theta$ equal $45^{\circ}$ beneficial in decreasing the uplift pressure to $40.3 \%$, seepage quantity to $28.5 \%$, as compared with the general case(no cutoff).

- Placing a cutoff at the hydraulic structure toe is not recommended under any angle of inclination to decreasing the value of uplift pressure.

- Using an inclined cutoff towards the downstream side with $\Theta=120^{\circ}$ beneficial in decreasing in value of exist gradient to $5.0 \%$ and increasing the safety factor against piping phenomenon to 3.18 .

- The reduction in uplift pressure, exist gradient and seepage when using double cutoff at $U / S$ with $\Theta=45$ and $\mathrm{D} / \mathrm{S}$ with $\Theta=120$ is more than that of using double cutoff at the up and downstream at right angle that given decreasing in value of exist gradient to $8.03 \%$, uplift pressure to $42.3 \%$, seepage to $31.15 \%$ and increasing the safety factor against piping phenomenon to 2.43

\section{References}

[1] AL-Ganaini,M.A., (1984),"Hydraulic StructurBeirut,pp47-60, (In Arabic).

[2] Selim, M.A., (1947) "Dams on Porous Media", TransactionASCE, Vol. 1 Roy, S.K.(2010). "Experimental Study OnDifferent Types Of Seepage Flow Under The Sheet PileThrough Indigenous Model.", M.Sc. Thesis Insoil Mechanicsand Foundation Engineering, University Of Jadavpur.12, pp488-526. 
[3] EL-Fitiany, M. A. Abourohim, R. I. and El-Dakak, A. Y.(2003) "Three dimensional ground water seepage around asimplehydraulic structure." Alexandria Engineering Journal,Volume 42 ,Issue 5, September.

[4] Arslan, C. A. and Mohammad, S. A. (2011)."Experimental andTheoretical Study for Pizometric Head Distribution underHydraulic Structures." Department of Civil engineering;College of engineering, University of kirkuk Volume 6 ,

[5] Musawi, W. H. 2002. Optimum Design of ControlDevices for Safe Seepage under Hydraulic Structures,M.Sc. Thesis, Department of Civil Engineering,University of Babylon.

[6] Zienkiewicz, O. C.(1982)."The Finite Element in Engineering Science" McGraw-Hill.
[7] Zienkiewicz, O.C. (1966): "Solution of anisotropic seepage by finite element", Journal of the Engineering Mechanic Division, Vol.(92), No.1, pp.111-120.ual, EM1110-2-1901, Chapter 4, Washington, D.C.,U.S.A.

[8] Selim, M.A. , (1947) "Dams on Porous Media", Transaction ASCE , Vol. 112, pp 488-526.

[9] Naamani, L., Turk, D. and Osman, H.(2002)."Finite Element analysis Versus Seepage Tank Model." Civil and Environmental Engineering.

[10] Ijam, A. Z.(2011)."Dams with an Inclined Cutoff." Civil and Environmental Engineering Department, Faculty of Engineering, Mu'tah University, Mu'tah, Jordan, Volume 16, p $1427-1440$. 